\title{
EDUCACIÓN AMBIENTAL EN EL CAPITALISMO
}

Guillermo Foladori ${ }^{1}$

\section{Resumen}

Este artículo destaca un principio metodológico que debe ser clave en la práctica de la educación ambiental. Se trata de la prioridad que debe darse a las implicaciones de las relaciones económicas sobre el ambiente en el sistema capitalista. El artículo muestra las principales tendencias de las relaciones capitalistas y sus implicaciones ambientales más destacadas. Ubica, por tanto, la problemática ambiental desde dos perspectivas. Por un lado, un enfoque histórico, en este caso restricto al sistema capitalista. Por otro lado, un enfoque jerárquico, donde se priorizan las relaciones económicas sobre otras, como las ideológicas o políticas, y se explica el porqué de esta centralidad.

Palabras clave: Ambiente. Crisis ambiental. Capitalismo.

\section{ENVIRONMENTALEDUCATION IN CAPITALISM}

\begin{abstract}
This article emphasizes a methodological principle that must be fundamental in the practice of environmental education. It is the priority that must be given to the implications of economic relations on the environment in the capitalist system. The article shows the main trends of capitalist relations and their most important environmental implications. Therefore, it situates the environmental problem from two perspectives. On the one hand, a historical approach, in this case, restricted to the capitalist system. On the other hand, a hierarchical approach, in which economic relations are prioritized to the detriment of others such as ideological or political, explaining the reason for this centrality.
\end{abstract}

Keywords: Environment. Environmental crisis. Capitalism.

\section{EDUCAÇÃO AMBIENTAL NO CAPITALISMO}

\section{Resumo}

Este artigo destaca um princípio metodológico que deve ser fundamental na prática da educação ambiental. Trata-se da prioridade que deve ser dada às implicações das relações econômicas sobre o meio ambiente no sistema capitalista. O artigo mostra as principais tendências das relações capitalistas e suas implicações ambientais mais importantes. Situa, portanto, a problemática ambiental a partir de duas perspectivas. Por um lado, uma abordagem histórica, no caso,restrita ao sistema capitalista. Por outro lado, uma abordagem hierárquica, em que as relações econômicas são priorizadas em detrimento de outras, como ideológicas ou políticas, explicando-se a razão dessa centralidade.

Palavras-chave: Ambiente. Crise ambiental. Capitalismo.

\footnotetext{
1 Profesor-investigador. Unidad de Estudios en Desarrollo. Universidad Autónoma de Zacatecas. gfoladori@gmail.com
} 


\section{Introducción}

Diversos enfoques se encuentran en los textos y prácticas de educación ambiental. Ellos reproducen losque se presentan en el análisis y discusión sobre la crisis y los problemas ambientales a nivel político e internacional.

El punto de partida de esos análisis es,siempre,identificarla causa de los problemas o la crisis ambiental. Aunque existen múltiples causas interrelacionadas para un problema ambiental, puede señalarse una jerarquía, o priorizarse aquella que es más estructural, de otras que son dependientes o circunstanciales.

Algunos autores enfatizan cuestiones ideológicas, por ejemplo religiosas; otros priorizan el nivel de desarrollo científico-técnico; aún otros destacan la política ambiental como elemento clave o desencadenante. Muchos autores han tratado el tema (GOLDBLATT, 1998; PASSMORE, 1978; WHITE, 1967).

En lo que sigue, tomamos partido por la interpretación que adjudica a las relaciones de producción la causa más profunda de la manera como el ser humano se relaciona con la naturaleza y, por tanto, también de la responsabilidad de tales relaciones económicas en la problemática o crisis ambiental contemporánea.

La priorización de las relaciones de producción tiene una explicación simple. Todo organismo vivo requiere apropiarse y transformar elementos, partes o espacios de la naturaleza para poder metabolizar, vivir y reproducirse. En esto el ser humano no se diferencia de los demás seres vivos.

Es conocido que muchas otras especies de seres vivos transforman los ecosistemas al punto que los convierten en áreas imposibles para su propia sobrevivencia. El caso, tal vez más notorio, es el de las cianobacterias, que hace alrededor de 2500 millones de años y durante varios millones fueron consumiendo el carbono del dióxido de carbono existente en la atmósfera y expulsando el oxígeno, con lo cual se incrementó el oxígeno atmosférico del uno o dos por ciento a los $21 \%$ existentes hoy en día, creando un ambiente planetario tóxico para ellas mismas (LOVELOCK, 1991).

Valga, también, mencionar que diverso tipo de crisis ambiental fue provocada por el ser humano aún en sus estadios menos avanzados del desarrollo material, como la extinción de mega fauna de aves y roedores en Australasia y América por cazadores y recolectores (ANDERSON, 2002; LEAKEY; LEWIN, 2008; STEADMAN et al., 2005).

La diferencia del ser humano frente al resto de los seres vivos, en lo que respecta al comportamiento con el ambiente externo, es el uso creciente y acumulado de instrumentos, que median la acción del cuerpo biológico con su entorno. Cada generación hereda, de las pasadas, un nivel ya dado de desarrollo de las fuerzas productivas, constituido por el saber práctico-científico, el nivel tecnológico, la infraestructura pre-establecida y un nivel poblacional y formas de organización de la división social del trabajo y de las clases sociales. A partir de ese bagaje material es que la sociedad humana tiene un grado de libertad para cambiar las condiciones, pero aquellas condiciones preexistentes limitan las posibilidades del cambio y presionan por su reproducción.

Todos esos elementos, mencionados anteriormente, están organizados por las relaciones sociales de producción, que es la base económica de cualquier metabolismo de la sociedad humana con el ambiente externo. Por eso, estas relaciones económicas son clave, y prioritarias para entender la problemática ambiental, más allá de las formas ideológicas y políticas que,aunquecon gran variedad y libertad de acción, deben someterse a las condiciones estructurales pre-establecidas por las relaciones de producción.

Para facilitar el análisis de las implicaciones ambientales de las relaciones de producción es útil agrupar tales implicaciones bajo dos conceptos: depredación y 
contaminación. Por depredación se entiende la utilización de recursos naturales con un ritmo, cantidad, o modalidad de extracción que hace imposible para los ecosistemas recuperarlos.

Cuando, a principios del siglo XX, comenzó a ser evidente esta práctica para los economistas, se la llamó economía de rapiña, un término muy adecuado para mostrar la apropiación privada de la fertilidad histórica que la naturaleza creó durante décadas, siglos, o miles de siglos como en el caso de muchos minerales(SOMBART, 1984).

Por contaminación se entienden los procesos económicos que lanzan al ambiente productos que alteran de tal forma los ecosistemas que constituyen un riesgo para la salud humana y de otras especies de seres vivos. Bajo estos dos conceptos, depredación y contaminación pueden englobarse todos los problemas ambientales; algunos de ellos son expresión de ambos conceptos. La Figura 1 ubica estos conceptos en relación al proceso productivo propiamente dicho.

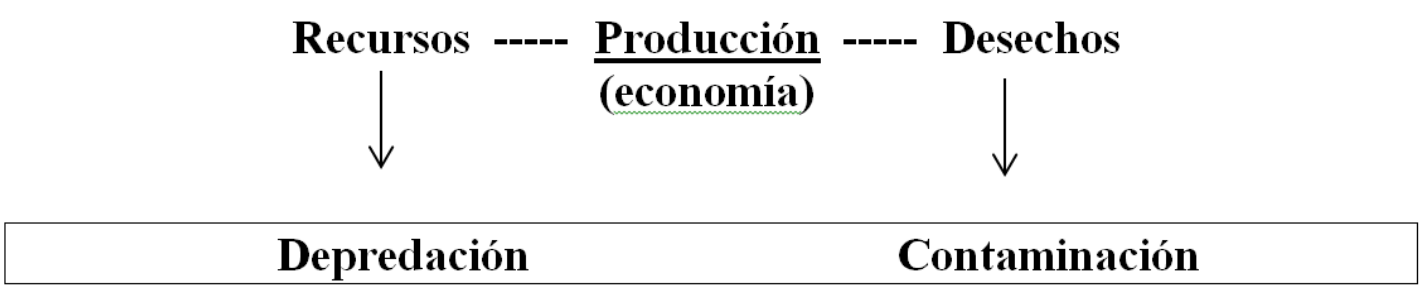

Figura 1. Esquema de problemas ambientales

Fuente: elaboración propia

Puede notarse que uno de los conceptos, la depredación, se ubica al inicio del proceso de producción porque los materiales o espacios retirados de la naturaleza entran al proceso de producción como materia prima.

El otroconcepto, la contaminación, se ubica durante y al final del proceso de producción, porque son desechos de las mercancías producidas, y cuyo ciclo de vida útil para el ser humano llegó a su fin. La contaminación se genera tanto durante el mismo proceso de producción como cuando las mercancías producidas son consumidas.

En cualquier caso, es el sistema de producción el que puede explicar la depredación y la contaminación; por ello, es necesario explicar la conexión de los problemas ambientales con las leyes económicas, en este caso capitalistas. No se consideran, aquí, los eventos extremos, propiamente naturales, que provocan contaminación o depredación de ecosistemas, como pueden ser las erupciones de volcanes, terremotos, huracanes o tsunamis.

\section{Principales tendencias de las relaciones capitalistas y sus implicaciones sobre el ambiente $^{2}$}

En lo que sigue, tratamos sólo de las principales categorías que explican la dinámica del sistema capitalista. Estas son: el valor, el plusvalor, la ganancia, la acumulación de capital y las crisis.

\subsection{El valor como relación social}

\footnotetext{
${ }^{2}$ Los apartados que siguen toman la explicación de las categorías económicas del libro A Economia da Sociedade Capitalista e suas crises recorrentes(FOLADORI; MELAZZI; KILPP, 2016). El lector puede acudir a él para una mayor explicación de las leyes tendenciales aquí anotadas.
} 
La generalización de la producción mercantil rompe con siglos de diferentes economías pre-capitalistas, donde la organización de los bienes necesarios y de la naturaleza transformada se realiza conforme sus características naturales. Sea cual fuera la organización social y el grado de desarrollo de las fuerzas productivas, todas las sociedades pre-capitalistas se caracterizan porque la producción (en cantidad, calidad, tipo de recurso natural utilizado, espacio explotado etc.) se orienta según las necesidades mismas que deben ser satisfechas con recursos naturales y espacios transformados específicamente a tales fines. El valor de uso que también es el contenido material de los productos comanda la producción.

La producción capitalista pone de cabeza la orientación de la producción según el valor de uso. La organización de los bienes, en tipo, cantidad, calidad, uso de determinada materia prima, apropiación de recursos naturales es regulada por los precios y el mercado, no por sus cualidades físicas o valor de uso. El metabolismo de la economía capitalista con el ambiente externo está totalmente regulado por los precios. Se sustituye una materia prima natural por otra, según los costos de producción y la potencial ganancia. Se explotan determinados recursos naturales según la ganancia que puedan brindar. Se concentra la población en determinados ecosistemas según las ventajas que las inversiones de capital ofrezcan.

El mercado establece, automáticamente, una equivalencia entre precios de mercancías y los materiales que son elaboradas con diferentes recursos naturales. De esta manera, los precios actúan como homogeneizador de diferentes productos naturales, como si con dinero se pudiera tener acceso a cualquier tipo de producto natural.

Cuando la política ambiental otorga precio a bienes naturales que no son mercancía, como animales salvajes, parques naturales, espacios de conservación, está suponiendo que el pago por tales bienes compensa el deterioro o depredación de la naturaleza; hace una equivalencia entre precio y naturaleza.

De igual forma, cuando se cobran tasas por contaminar, se supone que con ese dinero se puede compensar la contaminación, o invertir en tecnologías no contaminantes; nuevamente se equipara precio y naturaleza. La realidad ha mostrado que no existe tal igualdad. La naturaleza se guía por leyes ecológicas, biológicas, termo-dinámicas y físicoquímicas que no son convertibles a dinero, ni se pueden revertir procesos naturales, no importa el capital que se invierta para tal fin.

El poseedor de dinero elije cómo gastarlo. De allí la falsa imagen de que es el consumidor el responsable por los efectos antrópicos sobre la naturaleza. Pero esta reflexión lineal oculta dos características más determinantes. La primera es que no es igual poseer una cantidad limitada de dinero que permite sobrevivir, que poseer una cantidad mayor de dinero, que permite comprar medios de producción y producir mercancías.

El primero consume lo que existe. El segundo es quien tiene el poder de transformar la naturaleza con las consecuencias degradantes, buscadas o no, pero implícitas. La segunda característica, que la reflexión lineal oculta, es que la tecnología que permite la transformación de la naturaleza no es neutra, ella misma es producida con el criterio de rendir ganancia, no de ajustarse a la dinámica ambiental.

La tecnología es,también, un producto humano, cuya producción obedece los precios. La introducción en el mercado de una nueva tecnología, por ejemplo, más limpia o menos depredadora, sólo es posible si su empleo colabora en incrementar la ganancia en relación a las tecnologías existentes. De manera que los medios de producción, que son el puente que tiene la sociedad humana para transformar la naturaleza, están determinados, orientados y creados bajo la camisa de fuerza de los precios, no de su efecto cuantitativo o cualitativo sobre la naturaleza externa. La tecnología no es neutra, y su uso tampoco es libre de implicaciones ambientales. 
Al mismo tiempo que la producción capitalista hace que toda la producción esté organizada por los precios y la ganancia, y no por los flujos de energía y materiales que respondan a demandas eco sistémicas, crea una nueva característica del mayor impacto ambiental: inaugura una etapa histórica regida por la producción ilimitada. Mientras las sociedades pre-capitalistas producen para satisfacer necesidades de manera directa, la sociedad mercantil y capitalista produce para el mercado, la satisfacción de necesidades sólo viene después que el producto logró venderse y obtuvo un equivalente dinerario.

El aumento de la cantidad de dinero, o más específicamente de la ganancia dineraria, es el objetivo de la producción capitalista, y, por ello, se produce siempre más, se crean nuevos productos que, a su vez generan nuevas necesidades. Se explotan nuevos recursos naturales, se inunda el mundo con mayores residuos. La tendencia a la producción ilimitada es intrínseca a la producción capitalista, y las críticas de la moderna economía política al sistema capitalista lo advierten(GARRIDO PEÑA, 1993).

\subsection{El plusvalor explica la modalidad capitalista de explotación de la fuerza de trabajo}

La principal característica de la relación capital-trabajo es que el costo de la fuerza de trabajo es siempre inferior al valor creado durante el proceso productivo. De esta forma, el capitalista paga el valor de la fuerza de trabajo y se apropia del excedente de valor creado, o plusvalor. Ahora bien, esta relación supone y reproduce implicaciones directas sobre la naturaleza.

El capitalismo inaugura el gran quiebre en el metabolismo de la sociedad humana con la naturaleza externa. La necesidad de concentrar la fuerza de trabajo, para su explotación asalariada en fábricas, genera una división campo-ciudad nunca antes experimentada. La ciudad pasa a concentrar la mayor parte de la población, con la consecuente ruptura del metabolismo con la naturaleza externa, al requerirse el traslado y almacenamiento de enormes volúmenes de alimentos para los trabajadores y de materia prima para los procesos industriales. Demás está decir que esto genera, también, creciente acumulación de desechos concentrados en ecosistemas que no consiguen digerirlos.

Además, la búsqueda por abaratar el capital constante invertido obliga a la explotación de nuevos materiales de la naturaleza, nuevos territorios, otros seres vivos. No sólo la tierra, cursos de agua, minas y demás atributos son apropiados por el capital, sino que los propios seres vivos y sus genes son objeto de restricción en el acceso por las variadas modalidades de propiedad intelectual.

La naturaleza interna del ser humano cambia. El obrero asalariado, separado de medios de producción es, también, desposeído de cualquier tipo de conocimiento; o al menos éste ya no es utilizado en los procesos productivos. El asalariado se convierte en un apéndice de la máquina y de la división social del trabajo. La especialización descompone los procesos de trabajo en tareas parciales, simples y repetitivas, despojando al asalariado de cualquier aplicación de su conocimiento al proceso productivo.

La máquina, el equipo técnico, la infraestructura concentran el conocimiento técnico, al estar diseñados con criterios racionales para ocupar la fuerza de trabajo con independencia de las condiciones subjetivas e individuales de ésta. El conocimiento y saber técnico quedan objetivados, principalmente en el capital fijo.

Mientras el artesano imprime al producto un conocimiento y experiencia subjetiva y personal, el obrero asalariado reproduce funciones mecánicas, perdiendo cualquier aporte personal más allá de su desgaste físico, y aún este último está sujeto a la sustitución por los procesos de automatización. Se trata de la degradación de la naturaleza humana.

De manera que la sociedad capitalista cristaliza en dos clases sociales básicas, una de las cuales es separada de sus condiciones objetivas de vida (medios de producción y acceso al 
suelo) y del conocimiento histórico (conocimiento técnico de procesos laborales). Cierto es que el capitalismo también crea diversas capas de técnicos y científicos, pero aún éstos quedan desposeídos de su saber y conocimiento, una vez que los resultados de sus invenciones son patentadas o restringidas en las diversas formas de propiedad intelectual, y apropiadas por el capital.

Debe resaltarse que la responsabilidad sobre el medio ambiente adquiere un claro carácter de clase. Como la transformación de la naturaleza sólo puede darse mediante el uso de medios de producción, y como éstos son propiedad de la clase capitalista, sólo la clase capitalista es la responsable por la transformación de la naturaleza, con las consecuencias en la degradación y depredación.

En las sociedades pre-capitalistas el control de los medios de producción principalmente el suelo- estaba diseminado en campesinos que producían de manera tradicional. Ahora, el control de los medios de producción está concentrado en grandes corporaciones que son las que disponen de los recursos y ejecutan las transformaciones sobre el ambiente.

\subsection{La ganancia capitalista, objetivo de la producción}

La ganancia supone la migración de los capitales de uno a otro sector económico, acompañando las variaciones en la oferta y demanda de los productos y su efecto sobre los precios.

La ganancia impacta al ambiente de muy diferentes formas. En este caso, sólo tratamos del impacto de dos formas de ganancia: la ganancia media, que es la clave del movimiento del capital, y la renta del suelo, que es la modalidad mediante la cual se apropia de ganancia quien explota un recurso natural monopolizable.

La producción capitalista no es una producción globalmente planificada, ni siquiera nacionalmente. Su base está en la libertad de producir de que gozan los empresarios. De manera que la cantidad y calidad de la suma de las mercancías producidas en un sector económico nunca corresponde con la demanda; por ello, los precios suben y bajan según la escasez o la abundancia.

Dicho de otra manera, oferta y demanda nunca coinciden en la sociedad capitalista. El resultado es que grandes cantidades de mercancía, que son, de hecho, transformaciones de recursos naturales, son desperdiciados en el sistema capitalista.

Demás está decir algo que cualquier persona constata en pocos años, y es que los productos tienen una vida útil crecientemente reducida, generando gran cantidad de desperdicio. Esto es resultado de varias fuerzas encontradas. Por un lado, del abaratamiento de la materia prima y pérdida de la calidad de los productos, que lleva al consumidor a sustituir los productos de consumo rápidamente. Por otro, del abaratamiento del precio de los mismos productos, que facilita la sustitución por nuevos. Por último, por el papel de la propaganda y las modas en reducir la expectativa en el tiempo de uso. En cualquier caso, el derroche de materia prima natural transformada es evidente.

La renta del suelo es la ganancia que se apropia el dueño de la tierra debido a la mayor fertilidad de su lote y/o del monopolio que puede ejercer sobre ella. Si algo resulta sorprendente es que muchos suelos pueden ser explotados con rendimientos decrecientes, durante mucho tiempo, mientras generan una renta del suelo creciente (FOLADORI, 2001). Esta posibilidad es la más palpable demostración de cómo el capital puede ganar a expensas de degradar la naturaleza externa. Por lo demás, Marx ha sido explícito en cómo el capital avanza sobre la naturaleza apropiándose de todo lo posible para incrementar su dinámica, al respecto escribe: 
[...] la explotación de la naturaleza entera, para descubrir nuevas propiedades útiles de las cosas; intercambio universal de los productos de todos los climas y países extranjeros; nuevas elaboraciones (artificiales) de los objetos naturales para darles valores de uso nuevos. La exploración de la Tierra en todas las direcciones, para descubrir tanto nuevos objetos utilizables como nuevas propiedades de uso de los antiguos, al igual que nuevas propiedades de los mismos en cuanto materias primas etc. (MARX, 1984, p. 361).

El capital sólo considera la naturaleza como recurso productivo para la valorización del capital; en ningún momento como un espacio de reproducción de la vida que tiene leyes propias de funcionamiento cuya alteración profunda puede causar catástrofes ambientales de alcance mundial.

\subsection{La acumulación de capital}

Cuatro características conceptuales explican este proceso de desarrollo capitalista en relación con la naturaleza. El ritmo de desarrollo es una de ellas. El sistema capitalista tiene como motor la ganancia y, para ello, deben competir los capitales, que, al hacerlo, imprimen una velocidad de desarrollo de la ciencia y la técnica, y de la productividad del trabajo nunca visto antes en la historia de la humanidad.

Con ello, la utilización de recursos naturales da un salto significativo, al igual que la generación de residuos. El nivel alcanzado es otra de estas características. Uno de los ejemplos más contundentes del avance de las fuerzas productivas, en este aspecto, es la creación de organismos genéticamente modificados y de nuevos seres vivos.

La extensión o amplitud sobre todo el planeta es otro cambio radical que el capitalismo impone; y, lo que falta por conquistar, como las profundidades de los océanos es sólo cuestión de tiempo. El análisis de estas características distingue la apropiación y transformación de la naturaleza por el capitalismo de cualquier otro modo de producción anterior.

La cuarta característica es la representación mental de estos procesos. Esta representación es contradictoria. Se inaugura con la mentalidad mecanicista que arranca desde el Renacimiento, contraponiéndose a la mentalidad religiosa, mitológica o simplemente tradicionalista. Esta mentalidad cristaliza con el desarrollo de la ciencia moderna durante el siglo XIX, cuando comienzan a aplicarse los conocimientos científicos directamente a los procesos productivos, y las grandes empresas incorporan laboratorios $\mathrm{y}$ centros de investigación propios.

La aplicación de la ciencia a la producción como fuerza productiva traslada a la técnica el conocimiento de las leyes de la naturaleza. El resultado es que todo ese conocimiento se objetiva en los procesos productivos, principalmente en el capital constante. De esta forma, el capitalista se apropia del conocimiento histórico alcanzado en su momento. Esta mentalidad sólo se preocupa por el incremento de las fuerzas productivas en la tarea inmediata que desarrolla. $\mathrm{P}$

Paralelamente, surge la reflexión más amplia sobre el impacto de los procesos productivos en la salud humana y el medio ambiente. El concepto de desarrollo sustentable, generalizado desde mediados de la década de los ochenta del siglo XX, expresa esa contradicción entre desarrollo material por un lado y degradación y depredación de la naturaleza por otro.

\subsection{Las crisis económicas}


Las crisis económicas, o los periodos de recesión como se los llama comúnmente, tienen un directo impacto sobre el ambiente, aunque contradictorio. La manifestación más visible de una crisis económica es el enlentecimiento de la producción y el desempleo. Es sabido que tan pronto se reduce el ritmo de producción se consume menos materia prima y se generan menos residuos. En ambos casos la naturaleza externa mejora, como consecuencia de explotarla menos. Un ejemplo es la reducción de la deforestación en la Amazonia, como resultado de la baja de los precios del ganado durante la crisis de 2008 (SHARON, 2009).

Por esta razón muchos analistas dicen que lo que no se logra con medidas políticas en materia ambiental se alcanza cuando hay recesiones (PERKINS, 2015). De igual forma, se puede argumentar que el desempleo obliga a consumir menos combustible, con la consecuente reducción de la contaminación que provocan los hidrocarburos.

Otro argumento para sostener que las crisis mejoran la situación ambiental es la presión por la eficiencia tecnológica. La caída de las ganancias, provocada por la recesión, obliga a buscar alternativas tecnológicas más eficientes, y esto acarrea un menor consumo de materia prima, menor volumen de desechos $\mathrm{y}$, como consecuencia, una mejora en las condiciones ambientales.

Los argumentos anteriores son, sin embargo, cuestionables, lo que no significa que no sean parcialmente ciertos. En cuanto a la reducción de la producción y el consumo, esto puede verse contrarrestado por la sobre explotación de los suelos y los recursos naturales. Es conocido el caso de la gran crisis de 1929 y sus efectos en el medio-oeste norteamericano que, al reducir muchos trabajos en las ciudades y en los ferrocarriles, obligó al desplazamiento hacia las zonas rurales, y los bajos precios de los productos agrícolas llevaron a aumentar los suelos en explotación aún bajo rendimientos decrecientes, agudizando la sequía y las tormentas de polvo (MCLEMAN et al., 2014).

También hay ejemplos de deforestación y sobre-explotación de otros recursos naturales cuando suceden crisis, algunos de los cuales mencionados en la investigación sobre el sudeste asiático luego de la crisis de 1997 (PAGIOLA, 2001).

Es conocido que cuando ocurren crisis económicas las políticas ambientales son entre las primeras en restringirse, o no aplicarse, lo cual es un argumento en contra de las ventajas ambientales de las crisis (BOWEN; STERN, 2010).

Además de los argumentos anteriores, debe destacarse el desperdicio de infraestructura que ocurre como resultado de las crisis financieras. Numerosas empresas cierran, y ellas tienen instalaciones que quedan abandonadas. Esta infraestructura fue construida a expensas de enorme cantidad de recursos naturales transformados y consolidados en edificios, caminos y maquinaria. Se trata de un desperdicio de naturaleza transformada que las crisis económicas provocan.

La crisis de la vivienda, del 2008, provocó el surgimiento de muchos pueblosfantasma en los Estados Unidos (CLARK, 2008). Tampoco debe perderse de vista que las crisis económicas conducen a una mayor concentración de la riqueza y un avance sobre la privatización de los bienes comunes. En el caso señalado anteriormente, la concentración de la propiedad de viviendas ha sido notable.

\section{Conclusiones}

Las páginas anteriores resaltan la importancia de establecer correspondencias entre las principales tendencias de la producción capitalista y el medio ambiente. Se analiza el valor, el plusvalor, la ganancia, la acumulación de capital y las crisis. Sin esta conexión, entre producción y medio ambiente, los esfuerzos de la educación ambiental pierden el sustento más profundo y objetivo para mostrar las causas de los problemas ambientales y las barreras a las que se enfrentan las medidas mitigadoras o compensadoras. 
La conexión entre relaciones sociales de producción y problemática ambiental no sólo muestra las causas más profundas de los problemas ambientales sino que, también, señala las clases principalmente responsables, que son aquellas que poseen los medios de producción que transforman el ambiente. Las relaciones de producción también explican cómo la transformación de la naturaleza externa provoca, simultáneamente, cambios en la naturaleza interna de la sociedad humana, en un proceso coevolutivo.

\section{Referencias}

ANDERSON, A. Faunal collapse, landscape change and settlement history in Remote Oceania. World Archaeology,Abingdon,v. 33, n. 3, p. 375-390, jan. 2002.

BOWEN, A.; STERN, N. Environmental policy and the economic downturn. Centre for Climate Change Economics and Policy Working Paper No. 18 Grantham Research Institute on Climate Change and the Environment Working Paper No. 16, jan. 2010. Disponível em: <http://www.lse.ac.uk/GranthamInstitute/wp-content/uploads/2014/02/WorkingPaper16.pdf>.

Accesoem:7 fev. 2018.

CLARK, A. For sale at $\$ 1,250$ : the Detroit houses behind the sub-prime disaster. The Guardian, Londres, 24 out. 2008. http://www.theguardian.com/business/2008/oct/24/subprime-crisis-usa-housingdetroit .Accesoem: 7 fev. 2018.

FOLADORI, G. El metabolismo con la naturaleza. Revista Herramienta, Buenos Aires, v. 6, n. 16,pp 81-97,jul. 2001.

FOLADORI, G.; MELAZZI, G.; KILPP, R. Economia da sociedade capitalista e suas crises recorrentes. São Paulo: Expressão Popular, 2016.

GARRIDO PEÑA, F. Introducción a la ecología política. Granada: Comares, 1993.

GOLDBLATT, D. Teoria social e ambiente. Lisboa: Instituto Piaget, 1998.

LEAKEY, R. E.; LEWIN, R. La sexta extinción: el futuro de la vida y de la humanidad. Barcelona: Tusquets, 2008.

LOVELOCK, J. As eras de GAIA. Rio de Janeiro: Campus, 1991.

MARX, K. Elementos fundamentales para la crítica de la economía política:Grundrisse. 1857-1858. 3 Tomos.Tradução José Aricó; Miguel Murmis; Pedro Scaron. México: Siglo XXI, 1984.

MCLEMAN, R. A. et al. What we learned from the Dust Bowl: lessons in science, policy, and adaptation. Population and Environment, New York City, v. 35, n. 4, p. 417-440, jun. 2014.

PAGIOLA, S. Deforestation and land use changes induced by the east asian economic crisis. EASES Discussion Paper Series,World Bank, Washington DC.mar. 2001.

PASSMORE, J. La responsabilidad del hombre frente a la naturaleza: ecología y tradiciones en Occidente. Madrid: Alianza, 1978.

PERKINS, S. Great Recession was good for the environment. Disponívelem: <http://www.sciencemag.org/news/2015/07/great-recession-was-good-environment>.Accesoem: 7 fev. 2018.

SHARON, B. How the Recession is Good for the Environment. Newsweek, 3 jun. 2009. Disponível 
em: http://www.newsweek.com/how-recession-good-environment-76311 Acceso em: 7 fev. 2018.

SOMBART, W. El apogeo del capitalismo. México: Fondo de Cultura Económica, 1984.

STEADMAN, D. W. et al. Asynchronous extinction of late Quaternary sloths on continents and islands.Proceedings of the National Academy of Sciences. National Academy of Sciences, 2005.v. 102, p. 11763-11768.Disponívelem: http://www.pnas.org/cgi/doi/10.1073/pnas.0502777102. Accesoem: 7 fev. 2018.

WHITE, L. The Historical Roots of Our Ecologic Crisis.Science, Washington DC.,v. 155, n. 3767, p. 1203-1207, mar. 1967. 